\title{
Looking at Physiological Anthropology from a Historical Standpoint
}

\author{
Tetsuo Katsuura
}

Ergonomics Section, Faculty of Engineering, Chiba University

\begin{abstract}
As one way of thinking about physiological anthropology, let us survey it from a historical viewpoint. At the beginning of the 19th century, Blumenbach, considered the father of Physical Anthropology, wrote his "Handbook of Comparative Anatomy and Physiology." The subsequent research conducted and papers written by researchers such as Broca and Martin pointed in the direction of physiological anthropology; furthermore, the research carried out by the American researchers Demon and Baker had a physiological anthropology "feel." The courses in Physiological Anthropology taught by Tokizane exerted a major influence on physiological anthropology in Japan. The precursor of the Japan Society of Physiological Anthropology, organized by Sato in 1978, was extremely significant in the effect that it had on the subsequent development of physiological anthropology. The holding of the biennial International Congress of Physiological Anthropology, along with the allocation of the Research sub-field of Physiological Anthropology in the Grantin-Aid for Scientific Research, would seem to suggest that the field of physiological anthropology is set to increasingly grow and evolve. J Physiol Anthropol Appl Human Sci 24(3): 227-229, 2005 http://www.jstage.jst.go.jp/browse/jpa
\end{abstract}

[DOI: 10.2114/jpa.24.227]

Keywords: physiological anthropology, physical anthropology, historical viewpoint

\section{The Origins of Physiological Anthropology}

It is difficult to say with precision when it was that physiological anthropology came into being; however, it can be stated that the beginnings of physiological anthropology research date back to the early 19th century (Table 1). The socalled "father of physical anthropology," Johann Friedrich Blumenbach (1752-1840), was a physiologist and anthropologist, in addition to being a professor at Goettingen University in Germany. In 1804, he wrote his "Handbook of Comparative Anatomy and Physiology," in which he argued that through the influence exerted by genes and climate, qualities peculiar to humans manifest themselves and racial differences start to appear. Based on measurements he took of cranial bones, he divided humans into 5 races: Caucasian, or the "white race"; Mongolian, or the "yellow race"; Malayan, or the "brown race"; African, or the "black race"; and American, or the "red race." Approximately half a century later, in 1861, the French anthropologist and pathologist Pierre Paul Broca (1824-1880) gave a talk at the Paris Anthropological Society (which he founded himself) about the motor speech area of the brain, which became famous as "Broca's area." This research clearly showed for the first time the existence of the functional localization of the cerebral cortex, and led the way forward to research into the higher functions of the nervous system in the domain of physiological anthropology. Furthermore, he advanced the science of cranial anthropology by developing a large number of new types of measuring devices and numerical indices, and laid down the foundations of French physical anthropology.

In 1914, Rudolf Martin (1864-1925), a professor at both Zurich and Munich Universities, published his "Textbook of Anthropology." In it, under headings such as "General Theory," "Somatology," "Morphology," "Physiology" and "Pathology," he summarized the various accomplishments that had been made in those fields up to that point. His demonstration of a system of anthropology that emphasized physiological and morphological techniques played an extremely important role in the development of physiological anthropology. Furthermore, in addition to the research he carried out into the physical anthropology of various racial groups in South-East Asia, he also established a standard method for the measurement of the human body.

The first research into physiological anthropology carried out in Japan can be traced back to 1954, when Professor Tokizane Toshihiko (1903-1973), at that time an associate professor in the Faculty of Medicine at the University of Tokyo, began lecturing on "Physiological Anthropology." As a world-renowned authority in neuro-physiology and electromyography, he was responsible for many remarkable achievements, and made a great contribution to the study of physiological anthropology in Japan.

Research into physiological anthropology has also been carried out in the United States over the last few decades. In 
1975, Prof. Albert Demon of Harvard University published a work entitled "Physiological Anthropology." A few years earlier, in 1968, he planned a symposium with the title of "Biological Adaptation in the City," to be held at the meeting of the American Anthropological Association (Demon, 1975), but as he himself has said, it turned out to be "a complete failure." Although research was carried out on Apaches on reservations in Arizona, the anthropological study of those living in urban environments was very poor (Sato, 1995).

Paul T. Baker, a professor of Biological Anthropology at Pennsylvania State University (retired, 1987) carried out research into (among other topics) cold adaptability in the high altitudes of the Andes, the effect of modernization on the peoples of Samoa, and population biology in Peru.

\section{What is Physiological Anthropology?}

From this historical standpoint, we can see that the study of physiological anthropology has evolved continuously within the broader sphere of anthropology or physical anthropology. It is said that anthropology is the field that considers the following: how did humans first appear, how have they evolved, and what kind of organisms are they in the present day? In other words, it is not merely enough to examine morphological characteristics - research must also be carried out into the physiological qualities of humans, and thought must be given to their evolution, adaptation and variation. Just as R. Martin places emphasis on the importance of physiological techniques, it is thought that the field of physiological anthropology is an indispensable part of the broader study of anthropology. However, it has to be said, unfortunately, that within anthropology, there has been little research done into physiological anthropology. Even in the case of researchers such as Blumenbach (credited as being the "father of anthropology"), and Broca (who set up the Paris Anthropological Society), although they were both responsible for some remarkable achievements in the fields of physiology and anthropology, those achievements do not in themselves constitute "research" in the pure sense of physiological anthropology. Although many anthropologists in the past made bones and fossils the object of their research, it is not possible to take physiological measurements using bones and fossils. Furthermore, the fact that many anthropologists were unaccustomed to taking physiological measurements was probably the reason behind the paucity of research into physiological anthropology. Therefore, it hardly needs to be said that the recent advances made in physiometrical apparatus have contributed greatly to the progress made in physiological anthropology research.

Within the field of anthropology, which investigates the scientific characteristics of humans, it can be said that physiological anthropology is a science in which physiological functions are the basis for researching the characteristics of human beings (Katsuura, 1983). The subjects used for research into such physiological traits have to be living human beings.
In other words, physiological anthropology is the anthropology of human beings living in our modern civilization (Sato, 1997). Thought of from another angle, the fact that very detailed and exhaustive research can be carried out on humans living now means that physiological anthropology has a distinct advantage over other branches of anthropology.

\section{The Development of Physiological Anthropology}

In the half-century since Prof. Tokizane first lectured on "Physiological Anthropology," the development of the field has seen steady progress. One example of this worthy of special mention is the formation of "The Conversazione on Physiological Anthropology," set up in November 1978 and numbering 51 voluntary members belonging to "the Anthropological Society of Nippon." At the center of the group was Prof. Masahiko Sato (1932-), a professor at the Kyushu Institute of Design. Subsequently, the name of the Conversazione was changed, first to the "Research Society of Physiological Anthropology," then in April 1987 to the "Society of Physiological Anthropology", then finally, in April 1993, to the name currently in use, the "Japan Society of Physiological Anthropology." In 1983, it published the first edition of its journal "The Annals of Physiological Anthropology," and then in January 1995, it established the English-language journal "APPLIED HUMAN SCIENCE Journal of Physiological Anthropology." From January of 2001, the title was changed once again to the "Journal of Physiological Anthropology and Applied Human Science." In addition, in February 1996, a Japanese sister journal was published for the first time, entitled "The Japanese Journal of Physiological Anthropology." Both the English-language journal (published 6 times a year), and its Japanese equivalent (4 times annually) carry many scientific papers relating to physiological anthropology, and both play a central role in research carried out in Japan.

Regarding international trends in physiological anthropology, the holding of the International Congress of Physiological Anthropology attracts a good deal of attention. In December 1991, the First International Congress of Physiological Anthropology was held in Tokyo. The Second was held in Kiel, Germany, in September 1994; the Third in Nara, Japan (Sept. 1996); Zagreb, Croatia, was the location for the Fourth Congress, in Sept. 1998; Seoul was the host for the Fifth in October, 2000, and Cambridge, England, was chosen for the Sixth International Congress, in August 2002. Memories are still fresh of the Seventh, held in Columbus, US, in September 2004. The Eighth is scheduled for October 2006 and will be held in Kamakura, Japan.

Something which was enthusiastically greeted by all those doing research in physiological anthropology was the designation (beginning fiscal 2003) of "physiological anthropology" as one of the research sub-fields eligible to receive Grant-in-Aid for scientific research funding from the Ministry of Education, Culture, Sports, Science and 
Table 1 Chronology of Physiological Anthropology

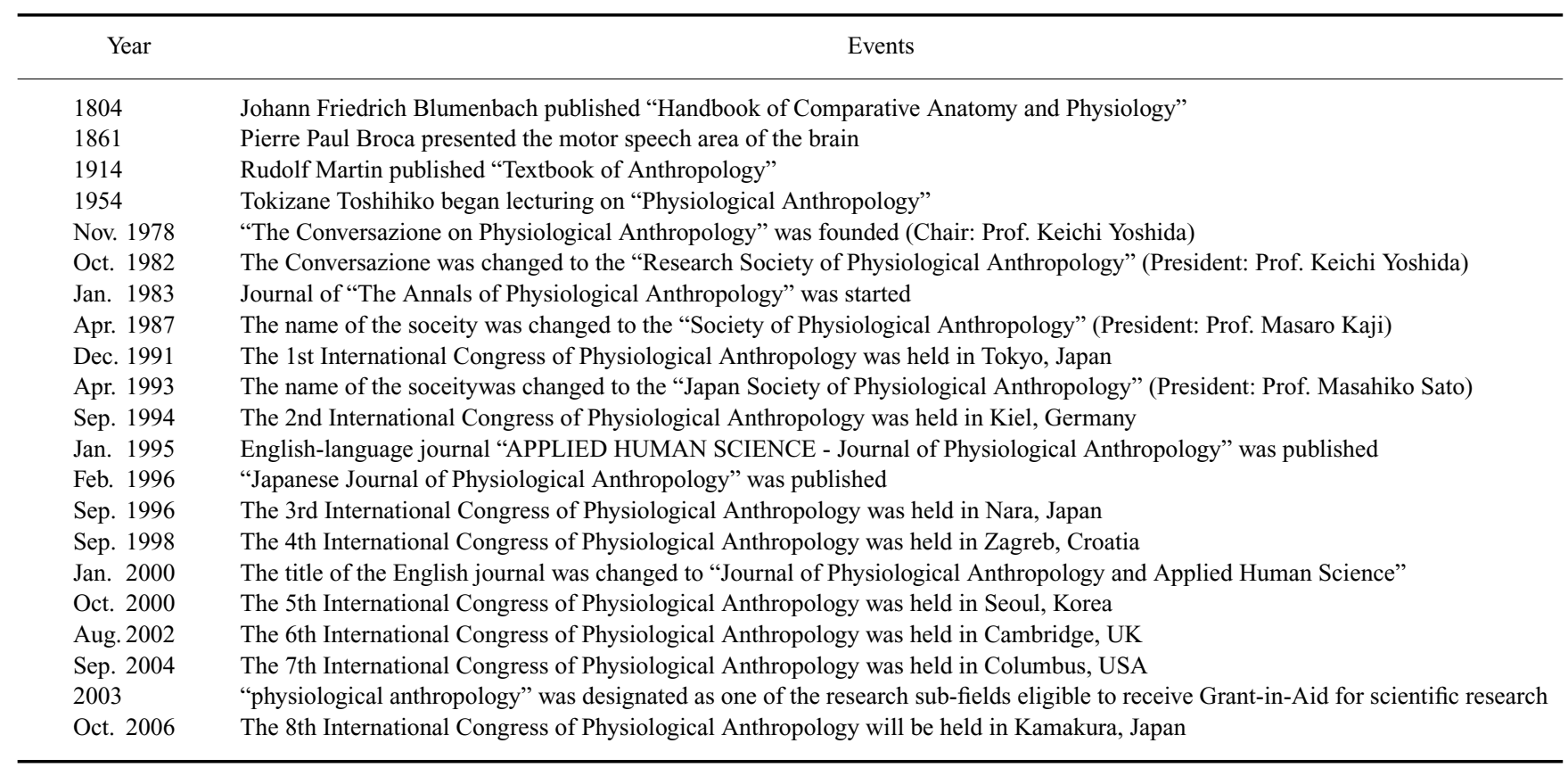

Technology and the Japan Society for the Promotion of Science. The securing of funds for scientific research is something of crucial importance for researchers, and it is thought that the specific inclusion of "Physiological Anthropology" as one of the areas eligible for research funding will accelerate the field's development hereinafter.

As previously stated, the significance of the establishment of Physiological Anthropology as a research sub-field eligible to receive Grant-in-Aid for scientific research is enormous. At the present time, the following areas of research are being carried out using the research funds allotted to Physiological Anthropology as mentioned above: Scientific Research S (4 issues), Scientific Research A (11 issues), Scientific Research B (7 issues), Scientific Research C (6 issues), Exploratory Research (7 issues), Encouragement of Young Scientists A (2 issues), and Encouragement of Young Scientists B (5 issues), bringing the total to 42 issues of research. These research fields are concerned in some way with each one of the five "Physiological Anthropology Keywords," namely: Environmental Adaptability, Technological Adaptability, Whole Body Coordination, Functional Potentiality, and Physiological Polymorphism. It is expected that the results of this research will be released and made public, which should have a major impact on the study of physiological anthropology in Japan. It is thought that more than ever before, research which gets to the very essence of physiological anthropology will flourish, and the scientific system of physiological anthropology will take shape.
Acknowledgments This work was supported in part by the Grant-in-Aid for Scientific Research (S) (grant No. 15107005) and the Grant-in-Aid for Scientific Research (A) (grant No. 15207021, 15207026) from the Japan Society for the Promotion of Science.

\section{References}

Demon A (1975) Biological Anthropology as an Applied Science. In Demon A ed. Physiological Anthropology. Oxford University Press, New York, 360-367

Katsuura T (1983) Physiological Anthropology. In Glossarist for Ergonomics ed. Encyclopedia of Ergonomics. Nikkankogyo Shinbunsha, Tokyo, 251 [In Japanese]

Sato M (1995) The Progress of Physiological Anthropology in Japan. Appl Human Sci 14: 1-4

Sato M (1997) Human Study and Physiological Anthropology. In Sato M ed. Contemporary Physiological Anthropology. Asakura-shoten, Tokyo, 1-5 [In Japanese]

Received: January 28, 2005

Accepted: March 18, 2005

Correspondence to: Tetsuo Katsuura, PhD., Ergonomics Section, Faculty of Engineering, Chiba University, 1-33 Yayoicho, Inage-ku, Chiba 263-8522, Japan

Phone: +81-43-290-3085

Fax: +81-43-290-3087

e-mail: katsu@faculty.chiba-u.jp 